\title{
BRASIL RURAL COMO ESPAÇO DE OPORTUNIDADES E PRIVAÇÕES: representações de uma categoria em transformação
}

\section{RURAL BRAZIL AS A SPACE OF OPPORTUNITY AND DEPRIVATION: Representations of a category in transformation}

\author{
Ada Cristina Machado da SILVEIRA ${ }^{1}$; Clarissa SCHWARTZ $^{2}$
}

Resumo: O presente artigo propõe-se a analisar as representações do rural brasileiro na televisão aberta nacional. A abordagem teórica reconhece o debate sobre as ruralidades e a emergência do novo rural brasileiro. A pesquisa busca apropriar-se de procedimentos da Teoria das Representações Sociais. O objeto empírico de análise escolhido foi a edição intitulada "A vida no campo" exibida pelo Globo Repórter, programa televisivo da Rede Globo de Televisão em 2015. Entre os resultados, apontamos que as representações do rural brasileiro veiculadas no programa oscilam numa polaridade definida pela themata que reconhece a oposição entre um espaço de oportunidades e ambiente de privações, construídas principalmente a partir de associações atribuídas ao urbano ou a distinções operadas desde o espaço urbano.

Palavras-chave: meio rural; representação social; televisão.

Abstract: This article proposes to analyze representations of the Brazilian rural in the national open television. The theoretical approach recognizes the debate on the ruralities and the emergence of the new Brazilian rural. The research seeks to appropriate procedures of the Theory of Social Representations. The empirical object of analysis chosen was the edition titled "Life in the field" exhibited by the show Globo Repórter, exhibited by Globo Television Network in 2015. Among the results, we point out that the representations of the Brazilian rural transmitted in the program oscillate in a polarity defined by the Themata that recognizes the opposition between a space of opportunities and an atmosphere of deprivation, constructed mainly from associations attributed to the urban or distinctions operated from the urban space.

Keywords: Rural environment; Social Representation; Television.

\footnotetext{
${ }^{1}$ Professora do Programa de Pós-Graduação em Comunicação da Universidade Federal de Santa Maria. Pesquisadora do CNPq. E-mail: adac.machadosilveira@gmail.com

2 Jornalista, Mestre e Doutora em Extensão Rural com estágio pós-doutoral em Comunicação. Membro do GP Comunicação, Identidades e Fronteiras - UFSM. E-mail: clarissaschwartz@ yahoo.com.br
} 


\section{Introdução}

A perspectiva desenvolvimentista amparada na Teoria da Modernização privilegiou historicamente a abordagem difusionista nos estudos de Comunicação dedicados ao meio rural. Duarte (2006, p.142), por exemplo, ao estudar as estratégias de transferência de tecnologia em bases sustentáveis para cadeias produtivas do agronegócio baseada no fluxo de informações, identificou que essa abordagem é preterida em favor do estudo dos fluxos financeiro e de produtos.

As proposições teóricas de autores como David Lerner, Wilbur Schramm e, especialmente Everett Rogers (CANTU; CIMADEVILLA, 2004; MATTOS, 2016), foram amplamente reconhecidas no que então nos coloca no âmbito do Terceiro Mundo necessitado de profundas transformações na ordem produtiva, sem atenção para a ordem social.

Afastando-nos dessa perspectiva e buscando reconhecer os estudos próximos ao que atualmente denominamos campo da comunicação (SODRÉ, 2011), abordagem bastante polemizada, buscamos conhecer as maneiras pelas quais a atividade televisual representa o meio rural. Entendemos que os estudos comunicacionais sobre a atividade televisual destinada aos temas do rural possuem uma larga história no Brasil, em que pese sua exígua quantidade.

O programa dominical Globo Rural da Rede Globo de Televisão, (posteriormente reprisado em diversos horários pela TV por cabo) consta na preferência dos estudos. Com o surgimento do canal segmentado da TV a cabo Canal Rural, novos estudos se dedicariam ao tema (SAPPER, 2006; CULAU, 2004).

O estudo do regime representacional da ruralidade tem, no registro de Cunha, Darde e Leme (2015) sobre o programa Globo Rural, a detecção de mudanças na representação dos moradores do campo nos últimos trinta anos na televisão brasileira:

Na década de 1980, a criação do programa Globo Rural aconteceu em um momento que o agricultor era representado na sociedade como um colono, reproduzindo ainda a visão dos imigrantes que vieram ao Brasil para começar uma nova vida e adotaram a produção de alimentos como forma [sic] sustento. Com o desenvolvimento econômico e social do país, ancorado no crescimento da produção de grãos e outros alimentos, a representação do homem do campo também foi se modificando. 
Atualmente, o perfil do homem do campo é bastante plural, com identidades que variam desde o agricultor familiar até o grande empresário do agronegócio (CUNHA, DARDE; LEME, 2015, p. 22).

Os autores salientam que a visibilidade dos moradores do campo na mídia contribui na construção de "um novo olhar sobre o campo e a atividade agrícola" (CUNHA; DARDE; LEME, 2015, p. 23).

No entanto, a força dos estereótipos associados ao rural e aos seus moradores persiste, conforme identificaram Bonomo e Souza (2013) em estudo sobre as representações hegemônicas e polêmicas sobre a identidade rural, realizado com um grupo de 200 moradores da zona rural do estado do Espírito Santo, no sudeste brasileiro. Os autores buscaram identificar metarrepresentações com o objetivo de reconhecer o lugar que o grupo estudado pensa ocupar no imaginário social urbano. Para os autores, os resultados - que podem ser exemplificados pelos depoimentos: "pensam que somos bobos, burros, cafonas, caipiras, jeca tatu, pobres e roceiros" (BONOMO; SOUZA, 2013, p. 413, grifo dos autores) - "indicam que o grupo rural reconhece a face hegemônica negativa de sua categoria de pertencimento" (BONOMO; SOUZA, 2013, p. 411) e que essa representação é associada pelo grupo às imagens divulgadas pelos veículos de comunicação de massa.

Considerando especialmente o valor da dimensão televisual na construção de representações sobre o rural, nos debruçamos na análise de produções audiovisuais relacionadas ao rural veiculadas na televisão aberta brasileira. Buscamos identificar se as representações consideram as múltiplas dimensões do rural, contemplando aspectos do novo rural brasileiro (GRAZIANO DA SILVA; DELL GROSSI; CAMPANHOLA; 2002) ou, por outra via, compreendem o rural apenas como um espaço de produção agropecuária.

O presente artigo se propõe a analisar o rural brasileiro na televisão aberta do país, buscando responder à indagação sobre como se atualiza sua representação. Elegemos como objeto empírico de análise o programa Globo Repórter da Rede Globo de Televisão, uma produção brasileira que está no ar desde 1973. O programa aborda desde 1993 um único tema por edição com o objetivo de aprofundar o assunto explorado (GLOBO REPÓRTER, 2017). A edição eleita foi veiculada em 20 de março de 2015 em TV aberta, composta por quatro grandes reportagens. Antes de passar a sua 


\section{míDiA \\ eco DiAno}

análise, abordamos aspectos teóricos fundantes das noções de ruralidades e seu entendimento no cenário de emergência do chamado novo rural brasileiro.

\section{Ruralidades e o novo rural brasileiro}

De acordo com o último censo agropecuário - realizado pelo Instituto Brasileiro de Geografia e Estatística há mais de uma década - o Brasil possui cinco milhões e 175 mil propriedades rurais que ocupam uma área de 329 milhões e 941 mil hectares ${ }^{3}$. Deste total, 84 por cento das propriedades são consideradas familiares, ocupam 24 por cento da área e 16 por cento não familiares concentram 76 por cento da área total. Entre os grupos de atividades econômicas mais comuns no campo brasileiro estão a pecuária e a criação de outros animais, a produção de lavouras temporárias e a produção de lavouras permanentes (IBGE, 2006).

Em um milhão e 100 mil estabelecimentos de agricultura familiar (25 por cento do total), os produtores declararam ter algum tipo de atividade fora do estabelecimento, sendo que 50 por cento declararam que essa atividade é agropecuária, 47 por cento declararam que são atividades não agropecuárias e três por cento que são atividades agropecuárias e não agropecuárias (IBGE, 2006).

São as atividades não agropecuárias que caracterizam o novo rural brasileiro conjunto de atividades não-agrícolas tais como moradia, lazer, atividades industriais e de prestação de serviços - num contexto que, segundo Graziano da Silva, Del Grossi e Campanhola (2002), começou a surgir no Brasil em 1980: “É preciso tomar o rural como um espaço de múltiplas dimensões e não apenas como um local onde se realizam atividades agropecuárias" (GRAZIANO DA SILVA; DEL GROSSI; CAMPANHOLA, 2002, p. 63). Conforme os autores, outros grupos de atividades básicas como a agropecuária moderna e ligada às agroindústrias e as atividades agropecuárias impulsionadas por demandas de mercado como floricultura, horticultura, etc., constituem, em seu conjunto, o rural brasileiro.

\footnotetext{
3 A partir de outubro de 2017 está previsto o levantamento de dados do novo censo agropecuário brasileiro. A previsão é de que os dados comecem a ser divulgados na metade de 2018 (PORTAL BRASIL, 2017)
} 


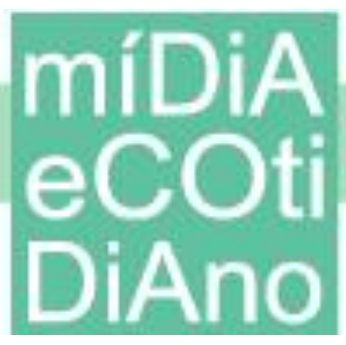

PPGMC

Essa diversificação coloca em destaque o homem do campo pluriativo ou as ocupações rurais não-agrícolas (Orna's). A pluriatividade seria uma unidade agrícola multidimensional com atividades agrícolas e não-agrícolas que podem ser exercidas dentro e fora do estabelecimento. Rendimentos, transferências e renda em espécie podem ser usados para pagar esses serviços (FULLER, 1990 apud KAGEYAMA, 1998). Atualmente, cerca de 28 por cento das pessoas ocupadas que vivem no meio rural do Brasil trabalham em atividades não-agrícolas como serviços públicos e privados (33,8 por cento), indústria (25,3 por cento) e comércio ( 16,8 por cento).

Ampliando o universo de análise, Centeno (2011, p.158) utilizando-se de dados da Organização das Nações Unidas (ONU) aponta que a América Latina possui uma população altamente urbanizada e que a população rural incrementou-se levemente nos últimos 50 anos, ainda que observe uma tendência de descenso. No entanto, ele aponta que, em que pese ter havido um incremento na população rural especificamente da América do Sul, os países do Cone Sul perderam 11,9 por cento de população nos últimos 50 anos. Apoiado em dados da fundação da ONU para agricultura e alimentação (FAO) de 2009, Centeno (2011) interpreta uma mudança também acusada no Brasil, referente à inversão da equação que fez com que a população urbana e não agrícola suplantasse a população rural.

Como resultado de um processo intenso de migrações do rural para o urbano, profundas transformações na vida social se fizeram sentir na sociedade brasileira em seus mais diversos âmbitos. A televisão, notadamente, contribuiu para reordenar simbólica e afetivamente a sociedade redefinida pela mobilidade social. Nesse contexto, vale considerar o questionamento acerca de como a modernização produtiva teria afetado o rural, especialmente em sua vocação agrícola.

Carneiro (1998) considera que o espaço rural não se define mais exclusivamente pela atividade agrícola e é crescente a procura de formas de lazer e até mesmo de meios alternativos de vida no campo, por pessoas vindas da cidade que buscam melhorar sua qualidade de vida. A autora também considera a ruralidade como um processo dinâmico reestruturado periodicamente através de novos valores, hábitos e também técnicas.

Wanderley (2000) aponta que o rural é uma categoria em transformação. A autora destaca que os avanços, nas mais diferentes áreas, causam uma redefinição das 


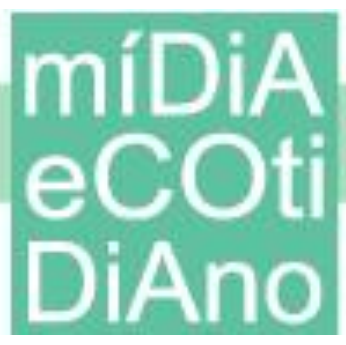

questões que envolvem o campo e a cidade, que teriam resultado na emergência de uma nova ruralidade. Em outras palavras, o campo realizaria uma ressignificação de suas funções sociais, perdendo o caráter de antagonismo com o meio urbano, passando a estabelecer uma relação de complementaridade com as cidades. As distâncias físicas e sociais foram sendo reduzidas por meio do acesso da população rural aos bens e serviços e também pelo aumento da renda dos moradores do campo.

Outro aspecto da discussão aborda os diversos grupos que compõem o cenário rural; eles podem enriquecer a dinâmica dessas comunidades, mas também representar fonte de conflito (WANDERLEY, 2000).

Essas posições variadas refletem justamente as múltiplas interpretações do que é o rural e os mais variados interesses. Seria um espaço destinado à produção? Um espaço de consumo visando melhor qualidade de vida? Um patrimônio ambiental que precisa ser preservado?

Essas interpretações variam de acordo com os critérios adotados para estudo. Mas, de modo geral. "este meio rural não é mais um espaço isolado do meio urbano; ao contrário, cada vez mais ele se insere, de modo diferenciado, sem dúvida, na sociedade moderna e incorpora suas mais profundas influências" (WANDERLEY, 2000, p.109). Outra interpretação acerca dessa nova ruralidade aponta para a existência de um continuum entre o meio rural e o meio urbano, que seria o reconhecimento de que "a passagem de uma comunidade rural para outra urbana se realiza de maneira gradual, de tal modo que entre o urbano e a ruralidade não há uma ruptura e sim uma continuidade" (DURÁN, 1998 apud WANDERLEY, 2000, p. 126). Carneiro (1998) lembra que esse processo de urbanização do campo se realizaria por meio principalmente da difusão de técnicas e também de costumes citadinos que culminariam com a perda das diferenças entre cidade e aldeia. A autora não acredita que aconteça uma homogeneização redutora da distinção entre o rural e o urbano a um continuum dominado pela cena urbana. Inclusive, para Carneiro (1998, p. 53), não se pode falar de ruralidade em geral, já que "ela se expressa de formas diferentes em universos culturais, sociais e econômicos heterogêneos".

\section{A análise das representações sociais}


A atividade televisual é aqui tomada como sistema de regras e convenções que reproduzem formas de representações sociais. A cultura brasileira está adaptada ao consumo de mensagens televisuais, dada a qualidade técnica e capilaridade do sistema de televisão, especialmente privada (MATTOS, 2000). Nossa análise apostou em um programa que observa vários aspectos do gênero do telejornalismo como estratégia de comunicabilidade, assumindo-o como uma forma cultural e uma instituição social de sentidos partilhados socialmente:

Trata-se de uma indústria de discursos, construídos a partir da gramática do televisual, cujas normas mais gerais são a serialização e a consequente fragmentação de suas narrativas; a mobilização e articulação de diferentes gêneros e de linguagens sonoras e visuais para sua expressão, sobredeterminadas pelos meios técnicos de produção, circulação e consumo dessas narrativas (DUARTE, 2013, p.2).

A produção televisual escolhida para ser analisada foi o programa Globo Repórter exibido pela Rede Globo de Televisão às sextas-feiras à noite. Inicialmente, fizemos uma busca no site do programa utilizando a palavra-chave "rural" que resultou em uma seleção de 13 vídeos que não ficou restrita ao objeto empírico e se expandiu também para outros programas como Globo Rural e programas de emissoras locais. Partimos, então, para a identificação das temáticas de cada edição em um período de dois anos (março de 2015 a março de 2017), o que totalizou 82 edições. O primeiro recorte distinguiu os programas que tiveram a localização no Brasil (54 edições) e em outros países (28 edições). Em seguida, identificamos as temáticas dos 54 programas realizados no Brasil (Quadro 1).

\begin{tabular}{|l|c|}
\hline Localização do programa & $\mathbf{N}^{\mathbf{0}}$ de edições \\
\hline Brasil & 54 \\
\hline Outros países & 28 \\
\hline Temas & $\mathbf{N}^{\mathbf{0}}$ de edições \\
\hline Economia & 5 \\
\hline Lugares do Brasil & 15 \\
\hline Hábitos/Comportamento & 15 \\
\hline Saúde/alimentação & 11 \\
\hline Festas/eventos & 4 \\
\hline Animais & 2 \\
\hline Outros & 2 \\
\hline
\end{tabular}


Quadro 1 - Localização e temas abordados pelo programa Globo Repórter entre março/2015 e $\operatorname{março/2017.~}$

Fonte: Elaboração das autoras a partir de informações do site www.g1.com/globoreporter

Apesar de a temática rural estar presente em diversos programas com reportagens específicas, especialmente nas edições que se dedicam a apresentar lugares diversos do Brasil - identificamos poucos programas em que o rural ocupa o protagonismo da edição: uma edição de economia, outra de hábitos/comportamento e a última sobre alimentação. São eles: "A vida no campo" (20/03/2015); Voltando às raízes (29/07/2016) e Orgânicos (14/08/2015). Nossa decisão de análise apresentada neste artigo recaiu no programa sobre economia intitulado "A vida no campo" que pretende abordar "o novo perfil do homem do campo no Brasil Central" (GLOBO REPÓRTER, 20/03/2015). O programa foi coproduzido pela Televisão Anhanguera, afiliada da Rede Globo em Goiás e Tocantins. As reportagens que formam o nosso corpus de análise estão listadas no Quadro 2.

\begin{tabular}{|l|l|l|l|l|}
\hline $\mathbf{N}^{\circ}$ & Título & Tempo & Assunto & Link \\
\hline 1 & $\begin{array}{l}\text { População de cidade } \\
\text { dobra com } \\
\text { oportunidades na } \\
\text { extração de minério }\end{array}$ & $6^{\prime} 45^{\prime}$, & $\begin{array}{l}\text { Desenvolvimento em cadeia } \\
\text { de uma cidade a partir de } \\
\text { oportunidades na extração } \\
\text { de minério }\end{array}$ & $\underline{\text { http://glo.bo/1AT9FZ1 }}$ \\
\hline 2 & $\begin{array}{l}\text { Modelo abandona } \\
\text { cidade para ganhar o } \\
\text { dobro vivendo no } \\
\text { campo }\end{array}$ & $7^{\prime} 11^{\prime \prime}$ & $\begin{array}{l}\text { As oportunidades de } \\
\text { trabalho geradas a partir do } \\
\text { desenvolvimento de uma } \\
\text { nova fronteira agrícola do } \\
\text { país }\end{array}$ & $\underline{\text { http://glo.bo/1FOECU0 }}$ \\
\hline 3 & $\begin{array}{l}\text { Vaqueiros ganham } \\
\text { até cinco salários } \\
\text { extras trabalhando em } \\
\text { hotel para bois }\end{array}$ & $7^{\prime} 51^{\prime \prime}$ & $\begin{array}{l}\text { As mudanças no campo } \\
\text { trazidas pela tecnologia }\end{array}$ & $\underline{\text { http://glo.bo/1Bf4vWy }}$ \\
\hline 4 & $\begin{array}{l}\text { Jovens do campo } \\
\text { buscam diploma e } \\
\text { conquistam salários } \\
\text { de até R\$ 15 mil }\end{array}$ & $15^{\prime} 37^{\prime \prime}$ & $\begin{array}{l}\text { Aumenta o nível de jovens } \\
\text { com ensino superior no } \\
\text { campo }\end{array}$ & $\underline{\text { http://glo.bo/1FOHLTN }}$ \\
\hline
\end{tabular}

Quadro 2 - Síntese do corpus de análise.

Fonte: Elaboração das autoras a partir do site www.gl.com.br/globoreporter

$\mathrm{Na}$ análise que apresentamos a seguir, buscamos identificar as representações sobre o rural construídas pelas reportagens. 


\section{míDiA \\ eco \\ DiAno}

\section{Representações de uma categoria em transformação}

A Teoria das Representações Sociais ocupa-se da interpretação da realidade, através da criação de símbolos e significados. A relação é aprofundada quando as reportagens veiculadas em TV aberta primeiramente estabelecem vínculos entre fato relatados e o contexto social, daí emergindo do processo as representações sociais.

A análise de representações sociais observa a abordagem de Serge Moscovici (2009) e é operacionalizada através de noções como themata, ancoragem e objetivação.

As representações sociais são "alguma coisa que emerge das práticas em vigor na sociedade e na cultura e que as alimenta, perpetuando-as ou contribuindo para a sua própria transformação" (SÁ, 1998, p. 50). O autor refere-se à construção e identificação do acontecimento objeto da representação social como problemática, pois "a existência ou não do fenômeno não é algo sempre evidente" (1998, p. 47).

A themata pode ser brevemente enunciada como uma ideia-primeira, ideia-fonte para a compreensão da criação das representações sociais (AMARAL; ALVES, 2013, p.72).

Além disso, pelo processo de ancoragem, salienta Jodelet (1993), as representações sociais e seu objeto se enraízam na sociedade de forma que as representações se convertem em instrumentos úteis, tanto para a comunicação como para a compreensão, pois ancorar as representações significa conectá-las com suas raízes no espaço e no contexto social, ou seja "[...] vinculá-lo, enraizá-lo aos seus valores, crenças, costumes preexistentes ao grupo social de onde a representação social saiu, articulando, em cada representação realizada por um grupo social, o novo com o velho" (JODELET, 1993, p. 381, tradução nossa). ${ }^{4}$

Já o processo de objetivação, segundo Jodelet (1993), permite que o objeto possa ser apreendido na medida em que aquela está incrustada, alojada e edificada em um saber comum, compartilhado por um grupo ou uma coletividade; ele busca reproduzir um conceito: "a concretização das ideias em imagens” (SÁ, 1998, p. 71).

\footnotetext{
${ }^{4}$ No original: “vincularlo, enraizarlo a sus valores, creencias, costumbres preexistentes al grupo social de donde la representación social salió, articulando, en cada representación realizada por un grupo social, lo nuevo con lo antiguo”.
} 
Apresentamos a seguir a análise de quatro reportagens buscando reconhecer a existência de thematas expressivas das noções de ruralidade assentadas e, talvez, a tentativa de exploração pelo programa televisual de uma nova noção. A análise busca identificar como ocorre o processo de objetivação das representações sociais na atividade jornalística, bem como sua ancoragem na atividade televisual veiculada.

\section{Brasil rural como espaço de oportunidades e privações}

A reportagem de $\mathrm{n}^{\circ} 1$ intitulada "População de cidade dobra com oportunidades na extração de minério" mostra como a atividade industrial no interior do município de Alto Horizonte em Goiás impulsionou o desenvolvimento econômico e social da cidade. Com a indústria há mais empregos, aumenta a renda dos moradores, são geradas novas oportunidades de trabalho no campo e na cidade e mais recursos são investidos no município, como exemplifica o texto da passagem do repórter. ${ }^{5}$

Toda essa riqueza mineral de Alto Horizonte segue para outros países. O transporte do que é retirado da mina ate os portos brasileiros, acabou virando uma alternativa de renda para os moradores da cidade. Eles tiveram a ideia de criar uma cooperativa de caminhoneiros. E começaram do zero. Eles já têm sede própria. São 42 sócios, cada um com seu caminhão (GLOBO REPÓRTER, 20/03/2015).

As imagens utilizadas para ilustrar a reportagem também enfatizam um vínculo de proximidade entre o rural e o urbano. Uma cena aérea mostra uma área urbana, com poucas construções, bem arborizada e cercada de campo. Nas ruas com "asfalto" como destaca o repórter - carros e bicicletas dividem espaço com carroças (Figura 1).

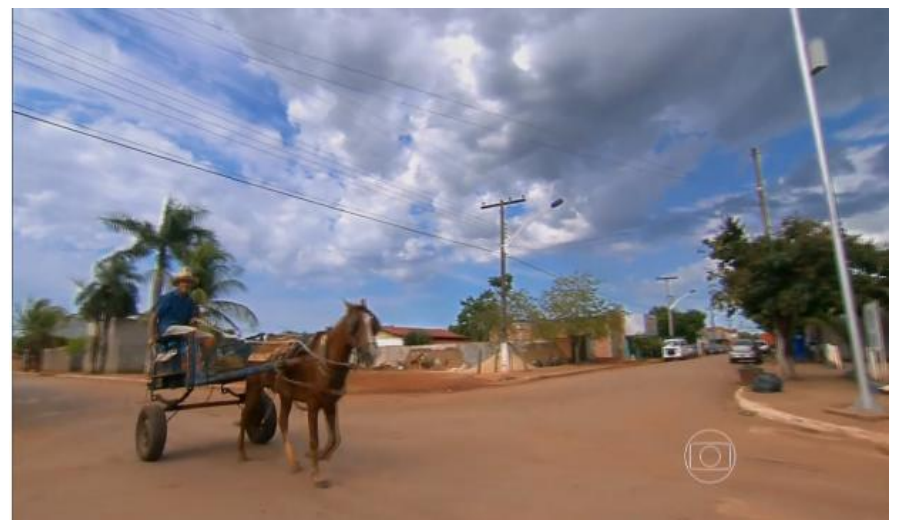

\footnotetext{
${ }^{5} \mathrm{O}$ termo Passagem designa o trecho da reportagem que marca a presença do repórter no local da notícia
} (SIQUEIRA; VIZEU, 2014). 
Figura 1 - Imagens destacam vínculos entre o rural e o urbano

Fonte: Reprodução Globo Repórter, 20/03/2015

Uma afirmação que atesta a objetivação produzida pela atividade televisual ocorre quando o repórter afirma que o circuito de desenvolvimento a partir da extração de cobre e ouro revela, na verdade, uma dependência: "É uma riqueza com prazo de validade, já que o minério é um recurso natural não renovável” (GLOBO REPÓRTER, 20/03/2015).

Sua ancoragem em noções assentadas ocorre quando o repórter enfatiza que o espaço rural não é ambiente exclusivo das atividades agropecuárias. A reportagem destaca um desenvolvimento em cadeia a partir de uma relação de complementaridade entre o campo e a cidade. Tais aspectos, de alguma maneira, são abordados pelos autores anteriormente referidos (GRAZIANO DA SILVA; DELL ROSSI; CAMPANHOLA, 2002; WANDERLEY, 2000).

A reportagem intitulada "Modelo abandona cidade para ganhar o dobro vivendo no campo" $\left(\mathrm{n}^{\mathrm{o}} 2\right)$ destaca uma nova fronteira agrícola do Brasil (conhecida por Mapitoba e inclui os estados do Maranhão, Tocantins, Piauí e o oeste da Bahia) que começa a ser explorada e desenvolvida com a chegada de pessoas de outras regiões e com maior grau de instrução. Para exemplificar, a matéria apresenta dois exemplos: um casal de São Paulo que investiu em um hotel e uma supervisora administrativa de um armazém de grãos (Helen, a modelo citada no título da reportagem) vinda do Mato Grosso. A produção de grãos integrada à indústria e fomento de outros setores - como a prestação de serviços - é destacada pela reportagem: "O casal viu que a ideia de investir em um hotel poderia dar certo ao perceber que a agricultura estava atraindo novos fazendeiros e, com eles, indústrias ligadas ao agronegócio” (GLOBO REPÓRTER, 20/03/2015). As imagens externas do hotel (fachada e obras de ampliação) instalado em um local ainda pouco urbanizado reiteram a relação de fomento entre campo e cidade (Figura 2). Os procedimentos jornalísticos podem ser tomados como uma ação sugestiva da ancoragem de concepções assentadas em representações sociais dominantes? 


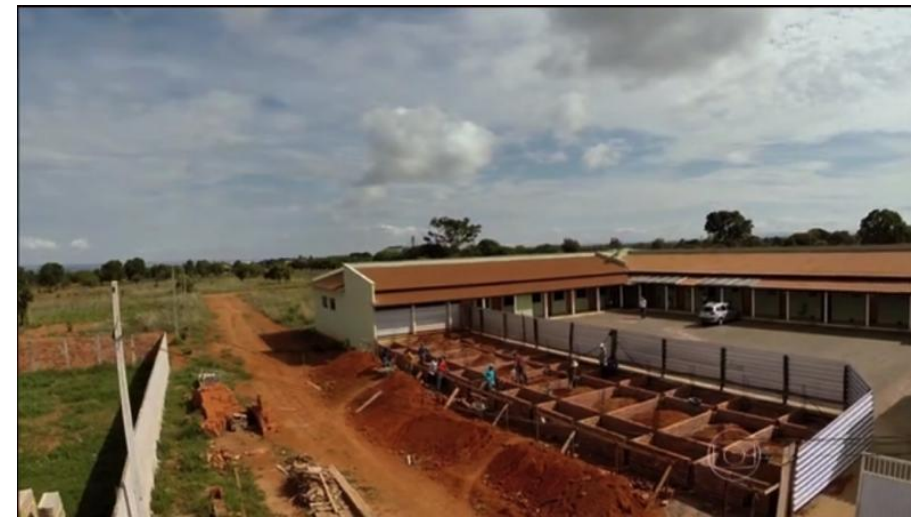

Figura 2 - Obras de ampliação de hotel em nova fronteira agrícola do Brasil

Fonte: Reprodução Globo Repórter, 20/03/2015

Apesar dos entrevistados destacarem as oportunidades encontradas na região como a melhor qualidade de vida (aspecto estudado por CARNEIRO, 1998), a reportagem enfatiza os problemas de infraestrutura, como podemos perceber na passagem do repórter:

Silvanópolis é um município carente de várias melhorias. Entre elas saúde e saneamento básico. O prédio da Prefeitura e da Câmara Municipal, por exemplo, é cercado de chão batido ainda. Bem diferente de outros centros agrícolas do país, mais desenvolvidos, com melhor infraestrutura. (GLOBO REPÓRTER, 20/03/2015, grifo nosso)

Entende-se, a partir da passagem, que a reportagem concebe o desenvolvimento como a presença do asfalto, do concreto, das vias de pedestres calçadas. É justamente a presença do "chão batido" em frente à Prefeitura que é referida pelo repórter como um traço da ruralidade que persiste e marca o atraso daquele município, percepção amparada no senso comum.

A reportagem ainda apresenta a vida na região como uma espécie de sacrifício. O texto "Helen se encantou com os grãos do cerrado. Até deixou de ser modelo" (GLOBO REPÓRTER, 20/03/2015) destaca a renúncia de uma carreira associada à beleza - mesmo mal remunerada - para trabalhar em uma região com problemas de 
infraestrutura. A entrevista de um engenheiro agrônomo também ressalta as dificuldades de viver na região: "Traz os desafios da falta de infraestrutura, mas nós temos produtores apaixonados com essa vocação indo para lá e desenvolvendo o agronegócio nessas regiões" (GLOBO REPÓRTER, 20/03/2015). Ou seja, o desenvolvimento da região rural referida depende de atores exógenos àquele espaço.

A matéria de $\mathrm{n}^{\mathrm{o}} 3$ intitulada "Vaqueiros ganham até cinco salários extras trabalhando em hotel para bois" aborda as mudanças que as tecnologias de informação e comunicação trouxeram para a profissão de vaqueiro (Figura 3). A utilização do computador, do rádio amador e do telefone celular pelos trabalhadores rurais é destacada pela reportagem como "uma mistura de vida pacata com o mundo moderno" e sinal de que "a roça não parou no tempo", indicando um processo de urbanização do campo ou projetando a temporalidade acelerada como lá adentrando.

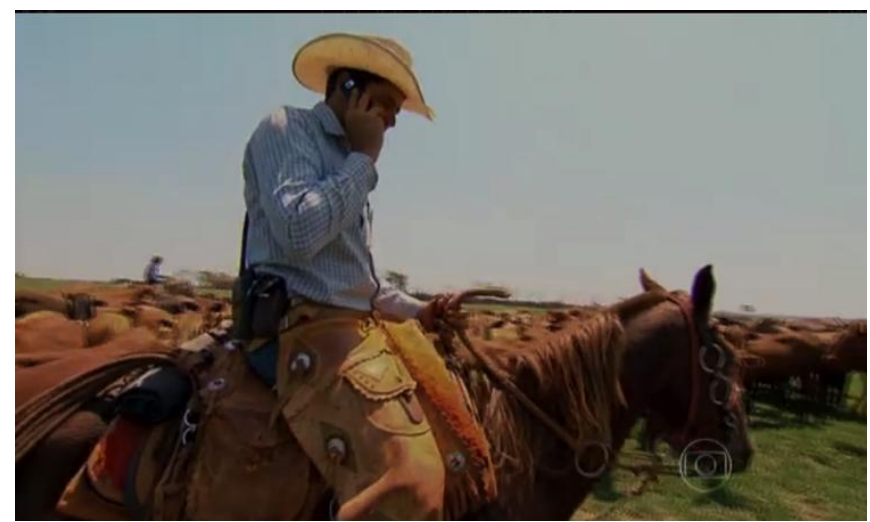

Figura 3 - Vaqueiro montado no cavalo tem rádio amador na cintura e fala ao celular Fonte: Reprodução Globo Repórter, 20/03/2015

Observam-se, no entanto, que as distinções entre o rural e o urbano são ressaltadas reiteradamente, tanto no texto em off como nos depoimentos dos entrevistados. $^{6}$

$\mathrm{Na}$ fazenda além de todos os direitos garantidos a um trabalhador com carteira assinada, o Wanderson e os colegas têm uma motivação a mais: eles enxergam no horizonte a possibilidade de ganhar salários extras. Um tipo de

\footnotetext{
${ }^{6}$ A expressão em off designa o texto gravado pelo repórter que tem imagens sobrepostas (SIQUEIRA; VIZEU, 2014).
} 
benefício que nem todas as empresas da cidade oferecem (GLOBO REPÓRTER, 20/03/2015, grifo nosso).

Se falar pra mim [sic] trocar a fazenda para ir pra cidade eu não troco não. Eu me sinto mais segura aqui, porque na cidade, sei lá, a violência tá maior, né? (esposa de vaqueiro, GLOBO REPÓRTER, 20/03/15, grifo nosso)

Há 15, 20 anos atrás, eu ia falar: 'vamos levar meu filho para cidade. Meu filho aqui tá ficando um roceiro, um bichinho do mato'. Agora não. Hoje não. Hoje eu tenho orgulho (pai de vaqueiro, GLOBO REPÓRTER, 20/03/2015, grifo nosso).

Nesse sentido, compreendemos que ao falar do rural, o programa Globo Repórter, que tem público majoritariamente urbano, busca estabelecer relações e/ou distinções contínuas entre o campo e a cidade, polarizando entre o tradicional e o novo, o conhecido e o emergente, numa ação de ancoragem, dado que as representações sobre o rural são construídas a partir de sua relação com o ambiente urbano onde se situa a maior parte das audiências de televisão e, principalmente, o interesse de seus anunciantes.

Assim como na reportagem de $\mathrm{n}^{\circ}$ 2, mesmo com os entrevistados destacando os pontos positivos de viver no meio rural, a migração para o campo é entendida como uma mudança forçada por circunstâncias extremas: "Por amor, Isabela trocou a cidade pelo campo", refere-se o repórter sobre a esposa de um vaqueiro que, depois do casamento, passou a viver no meio rural.

A reportagem de $n^{\circ} 4$ intitulada "Jovens do campo buscam diploma e conquistam salários de até R\$ 15 mil” aborda o aumento do nível de instrução dos moradores de zonas rurais. O primeiro off da reportagem destaca a qualificação profissional como possibilidade de mudança de vida para quem é oriundo do campo: “Eles são jovens. E o que mais têm em comum? Formam uma geração de 'doutores' do campo. Estão atrás ou já conquistaram o tão sonhado 'canudo' da faculdade e querem prosseguir, agora em melhores condições, a vida que os pais começaram na roça" (GLOBO REPÓRTER, 20/03/2015, grifo do autor). As imagens utilizadas para ilustrar o início do off da reportagem ressaltam as melhores condições referidas pelo repórter. Um grupo de estudantes universitários, vestindo jalecos brancos, faz experimentos em um laboratório, o que contrasta com outras cenas da reportagem em que trabalhadores rurais operam máquinas agrícolas sob poeira e sol forte (Figura 4). 


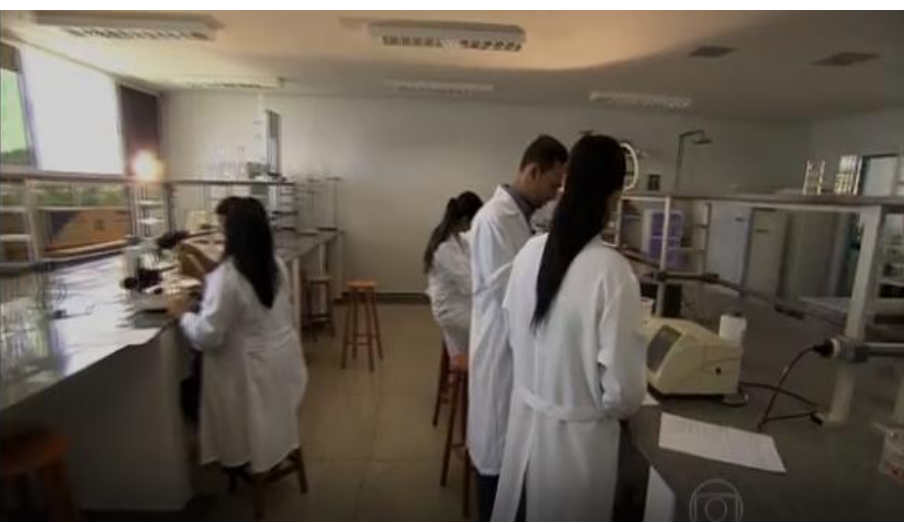

Figura 4 - Reportagem destaca os jovens oriundos do campo que buscam ensino superior Fonte: Reprodução Globo Repórter, 20/03/2015

A passagem apoia-se no senso comum da ascensão social por meio do estudo e reitera sua importância: "Uma realidade cada vez mais comum entre os filhos de trabalhadores rurais. Eles crescem e decidem continuar no campo. Aproveitar as oportunidades que o campo oferece e para isso vão em busca de um diploma" (GLOBO REPÓRTER, 20/03/2015). No mesmo propósito, o caminho percorrido pelos filhos de agricultores que, após buscarem qualificação, retornam ao campo para trabalhar é apresentado como a realização de um sonho para as famílias e para os jovens. Diferentemente do que percebemos nas reportagens de $n^{\circ} 2$ e 3 -em que a migração da cidade para o campo é apresentada como a privação de recursos existentes nos centros urbanos - o retorno ao campo para quem é oriundo do meio rural é tratado como um percurso natural e próspero. Trata-se de um recurso de objetivação do discurso televisual diferenciado que busca dar conta da dimensão economicamente mais expressiva do rural modernizado.

A reportagem termina com a história de uma família de agricultores de Santa Catarina que chegou a Goiás com pouca estrutura, mas através de muito esforço - e com a colaboração dos filhos que buscaram qualificação - é apresentada como um exemplo de sucesso profissional. Assim com na reportagem de $n^{\circ} 3$, busca-se fazer associações aos empreendimentos urbanos e mostrar as influências da cidade no modo de administrar uma fazenda: os agricultores passam a ser denominados empresários do agronegócio que trabalham em fazendas modernas e que têm escritórios (GLOBO 


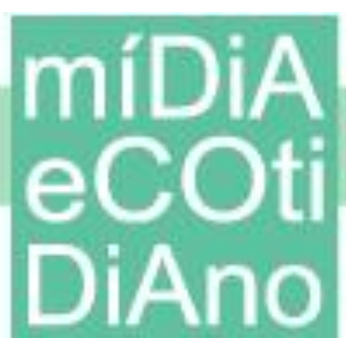

REPÓRTER, 20/03/2015). O processo de objetivação, talvez, decorra de uma tentativa de distanciá-los da face hegemônica negativa associada aos grupos de agricultores, referida por Bonomo e Souza (2013, p. 411). Com o Quadro 3 buscamos sintetizar as representações identificadas no conjunto de reportagens analisadas.

\begin{tabular}{|l|c|}
\hline Objetivação & Reportagem \\
\hline Atividade industrial traz desenvolvimento para o campo & $1,3,4$ \\
\hline O rural tem outras dimensões além das atividades agropecuárias & $1,2,4$ \\
\hline Campo e cidade estabelecem relação de complementaridade & $1,2,3,4$ \\
\hline O rural é um espaço a ser explorado e desenvolvido por atores exógenos & $1,2,4$ \\
\hline Migração da cidade para o campo não é uma mudança natural & 2,3 \\
\hline Falta infraestrutura no interior & 3,4 \\
\hline Tecnologias de informação e comunicação terminaram com o isolamento do meio & $1,2,3,4$ \\
\hline rural & $1,2,3,4$ \\
\hline Campo é espaço de oportunidade para os jovens & $1,2,3,4$ \\
\hline Falar sobre o rural é falar sobre sua relação com o urbano & 4 \\
\hline O meio rural tem cada vez mais mão de obra qualificada & \\
\hline Retorno ao campo entre os jovens rurais é um percurso natural & \\
\hline
\end{tabular}

Quadro 3 - Síntese das representações sobre o rural identificadas no corpus de análise

Fonte: Elaboração das autoras

\section{Considerações finais}

A análise das reportagens selecionadas no corpus permitiu identificar diversas representações sobre o rural brasileiro amparadas em elementos pseudoconceituais. Em que pese o programa ter como objetivo mostrar apenas uma realidade, a do Brasil Central, a partir de exemplos especialmente positivos, de pessoas que alcançaram sucesso profissional no meio rural, diversas dimensões puderam ser assinaladas, abarcando imagens genéricas de temas como a diversificação de atividades econômicas presentes no campo; as relações entre campo e cidade; as migrações; a melhora da infraestrutura e a qualificação da mão de obra disponível no interior.

Verificamos que campo e cidade são apresentados a partir de um ponto de vista apoiado numa crença social de integração, tanto que, ao falar sobre o rural, são utilizadas reiteradas comparações com o cotidiano urbano. A partir disso, entendemos 


\section{míDiA

que há uma construção das representações do rural operada a partir das relações entre o campo e a cidade pela perspectiva do senso comum.

Conforme as reportagens demonstram, talvez seja possível identificar a ancoragem que se vislumbra diante da nova ruralidade ou ao desenvolvimento do campo baseado na agroindústria. Ela consistiria em superar a associação de uma privação à migração reversa da cidade para o campo, responsável pelo retrocesso em que os habitantes do meio rural a ele retornariam, enquanto que o padrão dos oriundos da cidade seria o de viver na zona urbana. Assim sendo, na nova perspectiva, a mudança para o campo, tradicionalmente compreendida com um retrocesso ou um sacrifício, busca ser substituída pela condição de jovens rurais que realizam sua qualificação e retornam para trabalhar na zona rural, celebrados com a denominação de doutores do campo. Produz-se, assim, a ancoragem da representação numa zona rural projetada agora como espaço de oportunidades.

Retornando à questão inicial, sobre se o rural não seria mais representado apenas a partir do ponto de vista da produção agropecuária, o programa analisado mostrou uma forte ligação da produção primária de grandes propriedades com a indústria e também com o setor de prestação de serviços. As reportagens, operando por meio da ancoragem, produzem o vínculo com uma visão que se está fazendo predominante de converter o meio rural como um espaço de oportunidades. Assim, ele começaria a ser visto como superando a themata referente a um passado de privações, baseada no sistema de oposições que articulava rural e urbano num dado esquema de valores. A proposta do programa de televisão, em coerência com a mensagem novidadeira inerente ao meio, estaria começando a explorar a ancoragem na realidade do novo rural e, especialmente, a existência das ruralidades diversas.

Sendo assim, o propósito do sentido proposto pelas reportagens consistiria em superar a ideia primeira (themata) do rural como um lugar de privações, em favor de um novo rural, uma ancoragem redefinidora dos sentidos atribuíveis ao rural proposta a partir do meio urbano. Entendemos que o programa de televisão objetiva, desta forma, interpretar como é possível para a televisão aberta ancorar uma categoria em transformação, como o é o rural, em manifestações consideradas inovadoras econômica e socialmente. 


\section{Referências}

AMARAL, L.. S.; ALVES, M. S. Themata. Cadernos CESPUC, Belo Horizonte, n. 23, 2013.p. 69-76. Disponível em:

<periodicos.pucminas.br/index.php/cadernoscespuc/article/download/8307/7187> Acesso em: abril 2015.

BONOMO, M.; SOUZA, L. (2013). Representações hegemônicas e polêmicas no contexto identitário rural. Avances em Psicología Latinoamericana, Bogotá, v. 31; n.2, p. 402-418.

CANTU, A; CIMADEVILLA, G. Comunicación y ruralidad. Vigência y obsolescencia de las teorias clássicas. In: CIMADEVILLA, G; CARNOGLIA, E. Comunicación, ruralidade y desarrollo. Buenos Aires: INTA, 2004. p. 200-230.

CARNEIRO, M. J. Ruralidade: novas identidades em construção. Estudos Sociedade e Agricultura. n. 11, Out. 1998. p. 53-75.

CENTENO, M.E. Governance del território en el corredor Quines-Candelaria, província de San Luis. San Luis: INTA, 2011.

CULAU, D. C. O canal rural no espaço agrícola em Cruz Alta. Dissertação (Mestrado em Extensão Rural) - Universidade Federal de Santa Maria, 2004.

CUNHA, R. R. C. da; DARDE, V. W. da S.; LEME, F. A. As contribuições da TV para o desenvolvimento do campo e construção de novas representações sobre o rural. Sessões do Imaginário. Porto Alegre, v. 20, n. 34, 2015, p. 18-26. Disponível em: <http://revistaseletronicas.pucrs.br/ojs/index.php/famecos/article/view/22102> Acesso em: 20 mar. 2016.

DUARTE, E. B. Como caracterizar qualidade em relação à produção da Rede Globo de Televisão? Estudos em Jornalismo e Mídia, Florianópolis, v.10, n.2, jan-dez, 2013. Disponível em: < http://encurtador.com.br/fhiEN> Acesso em: 10 jan 2015.

DUARTE, J. Metodologia para análise de processos de comunicação em cadeias produtivas do agronegócio. In: DUARTE, J.; RIBEIRO, R.M. Comunicação em ciência e tecnologia. Brasília: EMBRAPA: 2006. p.139-170.

GLOBO REPÓRTER. Conheça a história do Globo Repórter. Rio de Janeiro, 09 março 2017. Disponível em: < http://g1.globo.com/globo-reporter/noticia/2010/04/conheca-historia-doglobo-reporter.html> Acesso em: 20 maio 2017.

GRAZIANO DA SILVA, DEL GROSSI, M; CAMPANHOLA, C. O que há de realmente novo no rural brasileiro. Cadernos de Ciência e Tecnologia. Brasília: Embrapa, v. 19; n.1 p. 37-67. Jan - Abr. 2002.

INSTITUTO BRASILEIRO DE GEOGRAFIA E ESTATÍSTICA. Censo agropecuário 2006. Rio de Janeiro, 2006. Disponível em:

<http://www.ibge.gov.br/home/estatistica/economia/agropecuaria/censoagro/1995_1996/default .shtm>. Acesso em: 30 set. 2009. 
JODELET, D. (Org.). Representações sociais. Rio de Janeiro: UFRJ, 1993. p.31-61.

KAGEYAMA, A. Pluriatividade e Ruralidade: Aspectos Metodológicos. Economia Aplicada, São Paulo, v. 2, n. 3, 1998. p.515-551.

MATTOS, S. A televisão no Brasil: 50 anos de história. Salvador: PAS/Ianamá, 2000.

Emile G. McAnany. Portal Metodista do Brasileirismo Comunicacional. Disponível em: <http://encurtador.com.br/gmqJ4> Acesso em: 20 junho 2017.

MOSCOVICI, Serge. Representações Sociais: Investigações em Psicologia Social. Trad. Pedrinho A. Guareschi. 6. ed. Petrópolis: Vozes, 2009. 404 p.

PORTAL BRASIL. Operações para o Censo Agropecuário 2017 começam em outubro.

Brasília, 03 abril 2017. Disponível em:<http://www.brasil.gov.br/economia-eemprego/2017/04/operacoes-para-o-censo-agropecuario-2017-comecam-em-outubro> Acesso em: 20 maio 2017.

SÁ. C. P. A construção do objeto de pesquisa em representações sociais. Rio de Janeiro: EdUERJ. 1988.

SAPPER, S.M Cenários de constituição de um dispositivo técnico-midiática voltado para o campo: realidades instituidoras do Canal Rural. In: DUARTE, J.; RIBEIRO, R.M. Comunicação em ciência e tecnologia. Brasília: EMBRAPA: 2006. p.597-622.

SIQUEIRA, F. C. de; VIZEU, Alfredo. Jornalismo em transformação: as escolhas dos formatos de notícias na TV. In: VIZEU, A. et al. Telejornalismo em questão. Florianópolis: Insular, 2014. p. 53-76.

SODRÉ, M. Comunicação: um campo em apuros teóricos. Matrizes, São Paulo, ano 5, n. 2 janjunho 2011. p. 11-27.

WANDERLEY, M. N. B. A emergência de uma nova ruralidade nas sociedades modernas avançadas - "o rural" como espaço singular e ator coletivo. Estudos Sociedade e Agricultura. Rio de Janeiro: CPDA/UFRRJ, n. 15, Out. 2000. p. 87-145. 